\section{Rates and Risk Factors of Staphylococcus aureus Nasal Carriage in Elementary School Children}

\section{To the Editor}

Staphylococcus aureus causes serious hospital and community-acquired infections all over the world (1). $S$. aureus colonize most frequently in the anterior nares of the nose of adults and children. The anterior nares of the nose are the primary reservoir of $S$. aureus, with approximately one-third of the general population colonized at any given time (2). Association between $S$. aureus nasal carriage and staphylococcal disease has been reported since 1931 (3). Risk factors for
S. aureus nasal carriage have been recently demonstrated, such as having a family member working in a hospital and having asthma $(2,4)$. The aim of this study was to determine the rates and risk factors of $S$. aureus nasal carriage in Turkish elementary school children. The study performed during the 10-months period from February to November 2007 in Ankara, the capital of Turkey. Seven elementary schools were randomly selected in this region. A total of about 4500 elementary school children aged between 7 and 12 years were enrolled. The 4097 nasal samples, taken with sterile cotton swabs, (CultureSwab Transport System; Difco, Detroit, Mich., USA) were obtained from children who agreed to the standard terms of informed consent. The nasal swabs were obtained from children and cultured onto $5 \%$ sheep blood agar plates (Oxoid, Hampshire, England) within 1-2 hours. Plates

Table 1. Comparison of demographic data of Staphylococcus aureus colonized and non-colonized children

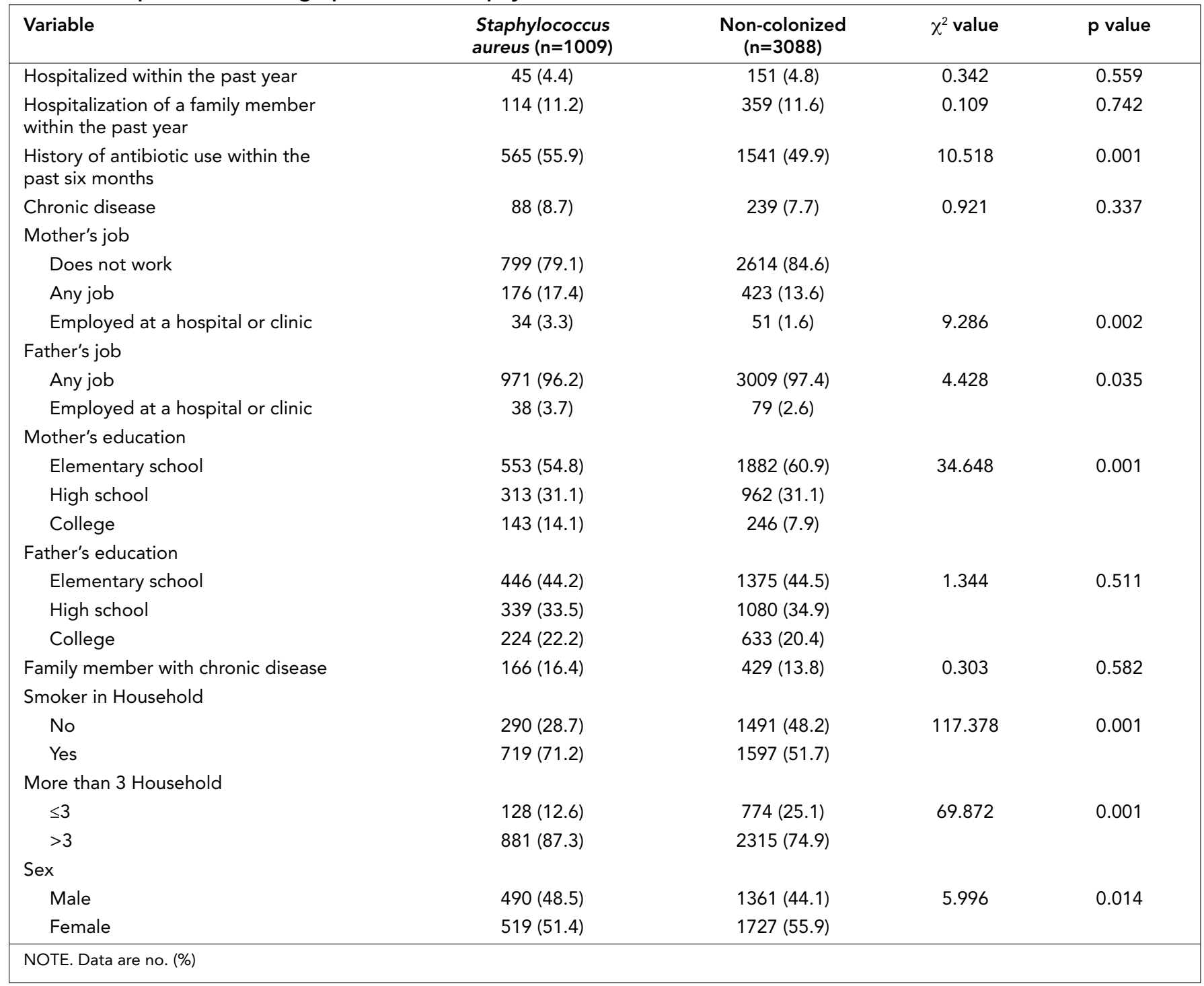


were incubated at $35^{\circ} \mathrm{C}$ aerobically for $16-18 \mathrm{~h}$. $\mathrm{S}$ aureus was identified by Gram stain, catalase and tube coagulase. S. aureus ATCC 29213 was used as a control strain. In this study, we evaluated nasal swab samples collected from 4097 children, including 1851 boys and 2246 girls. The median age of study participants was 8 years (range, 7-12 years). We found that $1009 / 4097$ (24.6\%) of children were colonized with S. aureus. Children colonized with $S$. aureus were not distinguishable from non-colonized in terms of hospitalization within 12 months, having chronic diseases, having a family member with chronic diseases, father's education. However, there was a statistically significant association between colonization rates and antibiotic administration history within the past six months, mother's education, family member employed at a hospital or clinic, smoker in households, more than three household members and sex (Table 1). $S$. aureus is one of the most important microorganisms causing hospital and community-acquired infection. It can cause serious infections including septicemia, pneumonia, endocarditis, and deep-seated abscess (5). The anterior nares of the nose is the site most frequently colonized with $S$. aureus. Other extra-nasal sites of the body include the skin, perineum, and pharynx harbor $S$. aureus (6). S. aureus carriage rates have been reported in various pediatric populations in the world. Immergluck et al. reported that $S$. aureus carriage rate was $18.6 \%$ in a total of 291 children (7). In another study, nasal carriage rate was reported as $24.4 \%$ in healthy children.(8). Kluytman et al. screened a total of 13.873 people in different studies and reported carriage rates between $19.0 \%$ and $55.1 \%$ (mean:37.2\%) (9). Wertheim et al. reported that $S$. aureus nasal carriage was $24 \%$, and carriers had a three-fold higher risk than non-carriers of acquired nosocomial $S$. aureus bacteremia (6). It was found that the prevalence of nasal carriage of $S$. aureus in the US population was $32.4 \%$ (10). In Turkey, nasal S. aureus carriage rates were found to vary from 19.1 to $38 \%$ in several studies $(4,11-14)$. In previous studies, the association between $S$. aureus nasal carriage and predisposing risk factors such as frequent hospital contact, antibiotic use history within past six months, family member working in a hospital or clinic, educational level of the mother and father, chronic illnesses, age, sex, and ethnicity have been investigated. A family member employed in a hospital or clinic, family size, and education of parents were found to significantly increase the risk of nasal $S$. aureus carriage (4, 15-17). In our study, antibiotic use history within the past six months, family member employed at a hospital or clinic, smoker in the household, mother's education, more than three household member and sex were associated with nasal S. aureus carriage. However, hospitalization within 12 months, having chronic diseases, having a family member with chronic diseases, father's education were not determined as a potential risk factor for nasal $S$. aureus carriage. As a result, nasal $S$. aureus carrier rates were high and some traditional risk factors were associated with nasal $S$. aureus carriage in Turkish elementary school children.

\section{Abdullah Kılıç, Ahmet Başustaoğlu \\ Deparmet of Medical Microbiology, Gülhane Military Medical Academy Ankara, Turkey Received: 6.2.2009 Accepted: 9.3.2009}

\section{References}

1. Chambers HF. Methicillin resistance in staphylococci: molecular and biochemical basis and clinical implications. Clin Microbiol Rev 1997;10:781-91.

2. Creech CB 2nd, Kernodle DS, Alsentzer A, Wilson C, Edwards $\mathrm{KM}$. Increasing rates of nasal carriage of methicillin-resistant Staphylococcus aureus in healthy children. Pediatr Infect Dis J 2005;24:617-21. [CrossRef]

3. Solberg CO. A study of carriers of Staphylococcus aureus with special regard to quantitative bacterial estimations. Acta Med Scand Suppl 1965;436:1-96.

4. Ciftci IH, Koken R, Bukulmez A, Ozdemir M, Safak B, Cetinkaya Z. Nasal carriage of Staphylococcus aureus in 4-6 age groups in healthy children in Afyonkarahisar, Turkey. Acta Paediatr 2007;96:1043-6. [CrossRef]

5. Kilic A, Li H, Stratton CW, Tang YW. Antimicrobial susceptibility patterns and staphylococcal cassette chromosome mec types of, as well as Panton-Valentine leukocidin occurrence among, methicillinresistant Staphylococcus aureus isolates from children and adults in middle Tennessee. J Clin Microbiol 2006;44:4436-40. [CrossRef]

6. Wertheim HF, Vos MC, Ott A, van Belkum A, Voss A, Kluytmans JA et al. Risk and outcome of nosocomial Staphylococcus aureus bacteraemia in nasal carriers versus non-carriers. Lancet 2004;364:703-5. [CrossRef]

7. Cheng Immergluck L, Kanungo S, Schwartz A, Mclntyre A, Schreckenberger PC, Diaz PS. Prevalence of Streptococcus pneumoniae and Staphylococcus aureus nasopharyngeal colonization in healthy children in the United States. Epidemiol Infect 2004;132:159-66.

8. Hussain FM, Boyle-Vavra S, Daum RS. Community-acquired methicillin-resistant Staphylococcus aureus colonization in healthy children attending an outpatient pediatric clinic. Pediatr Infect Dis J 2001;20:763-7. [CrossRef]

9. Kluytmans J, van Belkum A, Verbrugh H. Nasal carriage of Staphylococcus aureus: epidemiology, underlying mechanisms, and associated risks. Clin Microbiol Rev 1997;10:505-20. [CrossRef]

10. Mainous AG 3rd, Hueston WJ, Everett CJ, Diaz VA. Nasal carriage of Staphylococcus aureus and methicillin-resistant $\mathrm{S}$ aureus in the United States, 2001-2002. Ann Fam Med 2006;4:132-7. [CrossRef]

11. Karabay O, Otkun MT, Yavuz MT, Otkun M. Nasal carriage of methicillin-resistant and methicillin-susceptible Staphylococcus aureus in nursing home residents in Bolu, Turkey. West Indian Med J 2006;55:183-7. [CrossRef]

12. Erdenizmenli M, Yapar N, Senger SS, Ozdemir S, Yuce A. Investigation of colonization with methicillin-resistant and methicillinsusceptible Staphylococcus aureus in an outpatient population in Turkey. Jpn J Infect Dis 2004;57:172-5.

13. Harputluoglu U, Egeli E, Sahin I, Oghan F, Ozturk O. Nasopharyngeal aerobic bacterial flora and Staphylococcus aureus nasal carriage in deaf children. Int J Pediatr Otorhinolaryngol 2005;69:69-74. [CrossRef]

14. Baysoy G, Arslan S, Karabay O, Uyan AP. Nasal carriage of Staphylococcus aureus in children with allergic rhinitis and the effect 
of intranasal fluticasone propionate treatment on carriage status. Int J Pediatr Otorhinolaryngol 2007;71:205-9. [CrossRef]

15. Kenner J, O'Connor T, Piantanida N, Fishbain J, Eberly B, Viscount $\mathrm{H}$ et al. Rates of carriage of methicillin-resistant and methicillin-susceptible Staphylococcus aureus in an outpatient population. Infect Control Hosp Epidemiol 2003;24:439-444. [CrossRef]

16. Shopsin B, Mathema B, Martinez J, Ha E, Campo ML, Fierman $A$ et al. Prevalence of methicillin-resistant and methicillin-sus- ceptible Staphylococcus aureus in the community. J Infect Dis 2000;182:359-62. [CrossRef]

17. Oguzkaya-Artan M, Baykan Z, Artan C. Nasal carriage of Staphylococcus aureus in healthy preschool children. Jpn J Infect Dis 2008;61:70-2.

Address for Correspondence: Dr. Abdullah Kıllıç Deparmet of Medical Microbiology, Gülhane Military Medical Academy Ankara, Turkey Phone: +903123043412 E-mail: abkilic@gata.edu.tr 